

\title{
Application of X-Ray CT to Study Diffusivity in Cracked Concrete Through the Observation of Tracer Transport
}

\author{
Ivan Sandi Darma ${ }^{1}$, Takafumi Sugiyama ${ }^{2}$, Michael Angelo B. Promentilla ${ }^{3}$
}

\begin{abstract}
This paper demonstrates the application of microfocus X-ray computed tomography (CT) to study solute transport in cracked concrete. Cracks in a cylindrical specimen of ordinary Portland cement (OPC) and fly ash mortar were induced using a splitting tensile test. Cesium Carbonate $\left(\mathrm{Cs}_{2} \mathrm{CO}_{3}\right)$ was then used as a tracer in the in-situ diffusion test with the aid of X-ray CT. Image analysis was also employed to measure the 3D crack geometry and tracer diffusivity from these CT images. The geometric tortuosity of the crack was approximately 1.25 irrespective of the crack opening width and whether fly ash was added or not. On the other hand, the constrictivity increased for the fly ash mortar having roughly the equivalent crack opening width. The measured diffusivity in the crack was controlled by both crack opening width and constrictivity. Results obtained from microtomographic images suggest that the entire crack space may not always be filled with the tracer. The diffusive transport of solute in cracks thus can be restricted from microstructure's point of view. Smaller crack opening would increase such restricted diffusion. Indications also suggest that the addition of fly ash would lead to the reduction of diffusivity through uncracked body of the mortar.
\end{abstract}

\section{Introduction}

During its service life, cracks typically arise in most of the concrete member. Concrete cracking can be caused by various factors such as; mechanical loading, temperature and moisture gradients, expansive chemical reaction, and drying shrinkage. Concrete cracking can adversely affect the durability of concrete structures because crack space can act as preferential channels that will allow more ions to penetrate. In order to allow more accurate prediction of the durability and service life of concrete structure, it is important to investigate the effects of cracking on the transport properties of concrete.

However, transport phenomena of solute in the crack space of concrete are not clearly understood. Solute can be transported in crack by either capillary absorption, diffusion or both. It is thought that the absorption takes place in air-filled crack in concrete. Hence, the transport of solute by the absorption would be faster than that of diffusion. On the other hand, for solute to diffuse in the crack, the crack space in concrete needs to be saturated with water. Meanwhile, the degree of saturation inside crack space is difficult to measure with certainty. This means that solute diffusion in the crack is controlled by

${ }^{1}$ Ph.D Student, Environmental Material Engineering Laboratory, Graduate School of Engineering, Faculty of Engineering, Hokkaido University, Sapporo, Japan. E-mail: i_sandi_darma@yahoo.com

${ }^{2}$ Professor, Environmental Material Engineering Laboratory, Faculty of Engineering, Hokkaido University, Sapporo, Japan.

${ }^{3}$ Associate Professor, Chemical Engineering Department De La Salle University, Manila, Philippines. the presence of liquid phase and the diffusion coefficient depends not only on the crack geometry but also on the level of saturation. In this regard, it is therefore necessary to clarify the transport mechanism in cracked concrete.

It appears that the quantitative relationship between crack geometry and diffusion is not yet clearly established. For example, Jang et al. (2011) have developed a parallel composite model to identify the diffusion coefficient of cracked concrete and the crack geometry factor. However, the crack geometry obtained was determined indirectly from fitted data and not through the direct observation of crack space. In this regard, X-ray computed tomography (X-ray CT) is a powerful tool to provide a non-destructive examination of void space in three dimensions (3D). Using synchrotron radiation as the $\mathrm{X}$-ray source, Landis et al. (2000) observed the internal crack growth in small mortar size of $4 \mathrm{~mm}$ diameter by 4 $\mathrm{mm}$ high cylinders loaded in uniaxial compression. They studied the changes in the crack surface area during each load increment. On the other hand, for specimens of centimeter size, a cone-beam system can be used with a microfocus X-ray tube as the source. For example, microfocus X-ray CT system has been used to characterize air void in air entrained mortar at a resolution of few order of micrometers (Promentilla et al. 2008). Kikkawa et al. (2012) also used this X-ray CT to visualize three-dimensional image of flexural cracks in mortar beams with size of $10 \times 20 \times 60 \mathrm{~mm}$. Using this microfocus $\mathrm{X}$-ray $\mathrm{CT}$, it is expected that the more precise description of $3 \mathrm{D}$ crack geometry in cracked concrete can be possible to be achieved.

In general, the X-ray CT method is a $3 \mathrm{D}$ imaging technique to visualize the distribution of density in the materials. To visualize the diffusion phenomena in materials using X-ray $\mathrm{CT}$, it is necessary to give enough 
contrast through density change using solute as a tracer. In recent years, this technique has been applied in numerous investigations to evaluate the diffusion in rocks. Among the several types of tracer being used, Iodide is one of the most commonly used tracer in diffusion test for rock. Polak et al. (2003) were able to track and quantify tracer $(\mathrm{NaI})$ diffusion from a fracture into and within the surrounding rock matrix over time using computed tomography (CT). Recently, through diffusion experiment using Potassium Iodide solution (KI) as a tracer, the 3D diffusion-accessible porosity and the distribution of concentration in dolostone has been reported (Al et al. 2013).

Solutions containing cesium have also been found to be an appropriate tracer to study diffusion in porous material. For example, diffusion of cesium as a tracer in sedimentary rock was investigated based from the concentration profiles calibrated with CT number as a function of transport distance (Cavé et al. 2010). In addition, cesium carbonate solution has been used as a tracer in cracked concrete because of its relatively large contrast in CT images obtained from microfocus X-ray CT (Kikkawa et al. 2012; Ikeda et al. 2012). Investigations that specifically intended to obtain the diffusion coefficient of cesium in cement paste have also been done by several researchers. Kumar et al. (1986) presented the values of the cesium effective diffusion coefficient by measuring the flux of ions across hardened cement pastes. Bucur et al. (2010) evaluated cesium apparent diffusion coefficient in mortar specimen using diffusion cell experiment.

In this paper, we demonstrate the application of micro-focus X-ray CT and image analysis to determine the three-dimensional crack geometry factors such as tortuosity and constrictivity. With the proposed X-ray CT technique coupled with in-situ cesium tracer diffusion test, the transport phenomena of solute particularly its diffusion inside the crack and through the mortar perpendicular to the crack wall would be further understood.

\section{Materials and method}

\subsection{Preparation of specimen}

Table 1 summarizes the two types of mix proportion used in this experiment. The Ordinary Portland Cement (OPC) and Type II fly ash specified in the JIS A6201 were used in this experiment. The water to binder ratio was fixed at 0.6. The maximum aggregate size was 1.7 $\mathrm{mm}$ with a density and absorption rate of $2.71 \mathrm{~kg} / \mathrm{m}^{3}$ and

Table 1 Details of mortar specimens.

\begin{tabular}{|c|c|c|c|c|c|}
\hline $\begin{array}{l}\text { Speci- } \\
\text { men ID }\end{array}$ & $\begin{array}{l}\text { Max. Agg. } \\
\text { size }(\mathrm{mm})\end{array}$ & $\mathrm{W} / \mathrm{B}^{* 1}$ & $\mathrm{~S} / \mathrm{B}^{* 2}$ & $\begin{array}{c}\mathrm{FA} /(\mathrm{OPC} \\
+\mathrm{FA})^{* 3}\end{array}$ & $\begin{array}{c}91 \text { days } \\
\text { compressive } \\
\text { strength }\left(\mathrm{N} / \mathrm{mm}^{2}\right)\end{array}$ \\
\hline OPC-06 & \multirow{2}{*}{1.7} & \multirow{2}{*}{0.6} & \multirow{2}{*}{2.0} & 0 & 21.2 \\
\hline FA-06 & & & & 0.3 & 28.7 \\
\hline
\end{tabular}

*1: water to binder ratio, *2: sand to binder ratio, *3: Fly ash (FA) replacement for Ordinary Portland cement (OPC)
$2.5 \%$, respectively. Fresh mortar was placed in steel molds with a size of $40 \times 40 \times 160 \mathrm{~mm}$ and then cured in water for 3 months.

\subsection{Pre-cracking of specimen using controlled splitting tensile test}

Cylindrical specimens of $20 \mathrm{~mm}$ in diameter and $40 \mathrm{~mm}$ in length were obtained from mortar blocks after 3 months of curing. In this experiment, the diffusion of tracer was planned to occur in one of the cutting faces of the specimen. Subsequently, heat-shrinkable tube was used to cover the lateral surface of the cylindrical specimen. Heat-shrinkable tube was used not only to prevent initial diffusion from the surface in the lateral direction but also to avoid sudden failure during the splitting tensile test. Controlled splitting tensile tests were then used to induce cracks in the specimen (see Fig. 1). A clip gauge was installed on one of the cutting face of the specimen. When the crack opening displacement (COD) reached a certain specified value, the specimens were then unloaded. As the crack tends to close to a certain extent after unloading, repetitive tests were performed to obtain the target COD. Finally, residual crack widths (crack opening width) of 51, 127 and $152 \mu \mathrm{m}$ were obtained at unloaded state as shown in Fig. 2. Furthermore, the specimens were immersed in water for 24 hours after pre-cracking for further saturation.

\subsection{Image acquisition using X-ray CT with tracer test}

\subsubsection{Microfocus X-ray CT}

$\mathrm{X}$-ray CT is a powerful technique for investigating the three-dimensional (3D) microstructure of a material. As summarized by Landis and Keane (2010), the concept of $\mathrm{X}$-ray microtomography is similar to that of Computed Axial Tomography (CAT or CT) scans in the medical field, in which a $3 \mathrm{D}$ digital image is reconstructed from a series of two-dimensional (2D) images or "slices." The internal structure of concrete can be determined based on the mapping of CT number associated with each voxel in 3D space. The spatial resolution of CT images may vary from sub-micron scale for CT systems using monochromatic parallel synchrotron radiation to few orders of microns for a polychromatic cone-beam obtained from

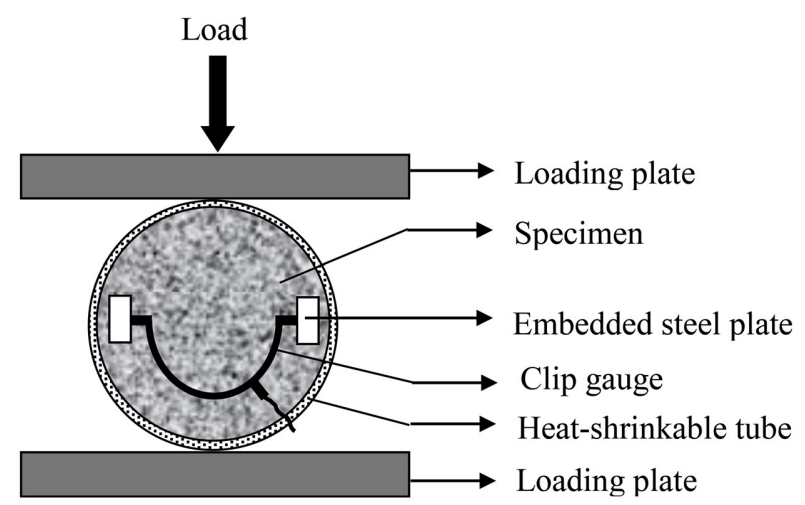

Fig. 1 Schematic diagram of the controlled splitting test. 

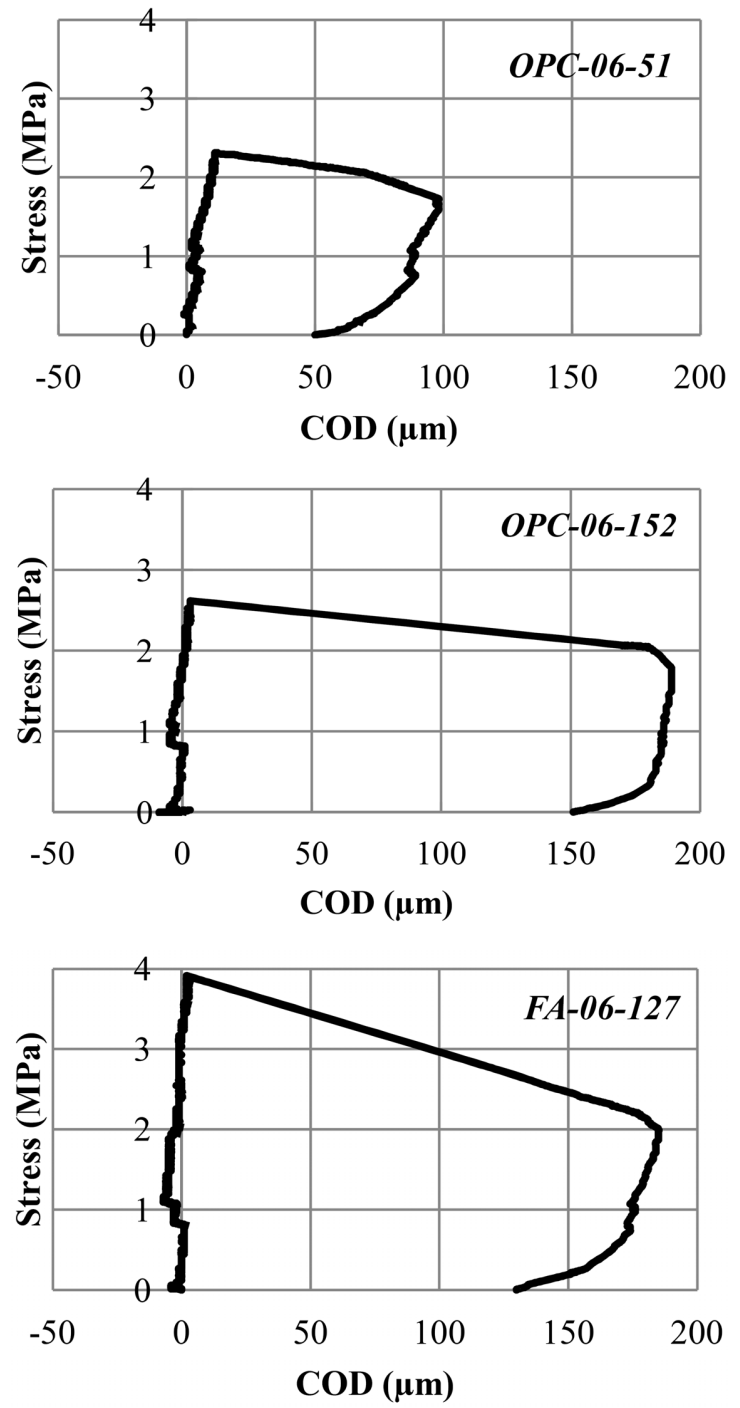

Fig. 2 Tensile stress-COD curves of each specimen.

microfocus X-ray CT. There is, however, a trade-off, such that the maximum sample size for the higher-resolution systems is limited to less than a few millimeters, whereas specimens on the scale of a few centimeters may be used with lower resolution systems. For cement-based materials, X-ray CT has been applied to a variety of research areas including pore structure characterization and freeze-thaw damage (Bentz et al. 2000; Burlion et al. 2006; Gallucci et al. 2007; Helfen et al. 2005; Lu et al. 2006; Hitomi et al. 2004; Promentilla et al. 2008, 2009, 2010; Sugiyama et al. 2010).

In this study, a desktop microfocus X-ray CT system was used to acquire the 3D image of the cracked specimen. The set-up (see Fig. 3) consists of a microfocus $\mathrm{X}$-ray emitter, a rotation table, an image intensifier (II) detector with CCD camera, and an image processing unit (Promentilla et al. 2008). The tube voltage and tube current of microfocus X-ray CT were set to a value of $130 \mathrm{kV}$ and $124 \mu \mathrm{A}$, respectively. The position of FCD (focus chamber distance) and FID (focus image distance) were set to 180 and $600 \mathrm{~mm}$, respectively. The focus area for data acquisition was approximately $16 \mathrm{~mm}$ in height and $20 \mathrm{~mm}$ in diameter. In this area, 366 slices of 44 micrometers thick were obtained. Each slice was 1024 by 1024 pixels in size, with each pixel 22 micrometers by 22 micrometers, for a voxel size of $22 \times 22 \times 44$ micrometers.

\subsubsection{Relationship between CT number and tracer concentrations}

A CT image is typically called a slice that displays differences in density and atomic composition at each of several thousand points in two-dimensional slice through the object. Each slice represents certain finite thickness, so by stacking up a series of contiguous slices, one can construct a continuous three-dimensional map of the density variations in the object that is expressed in terms of CT number. CT number or Hounsfield unit measures $\mathrm{X}$-ray linear attenuation of component inside the voxel that represents finite volume with dimensions defined by pixel resolution and slice thickness.

In case of diffusion, the movement of solute is caused by concentration gradient between source solution and internal crack space. In specific exposure time, the gradient of solute concentration occurred along the crack. This phenomenon can be observed clearly through X-ray CT by using a tracer with its CT number as an indicator of solute concentration. Therefore, a calibration to describe the relationship between $\mathrm{CT}$ number and solute concentration is needed for further analysis.

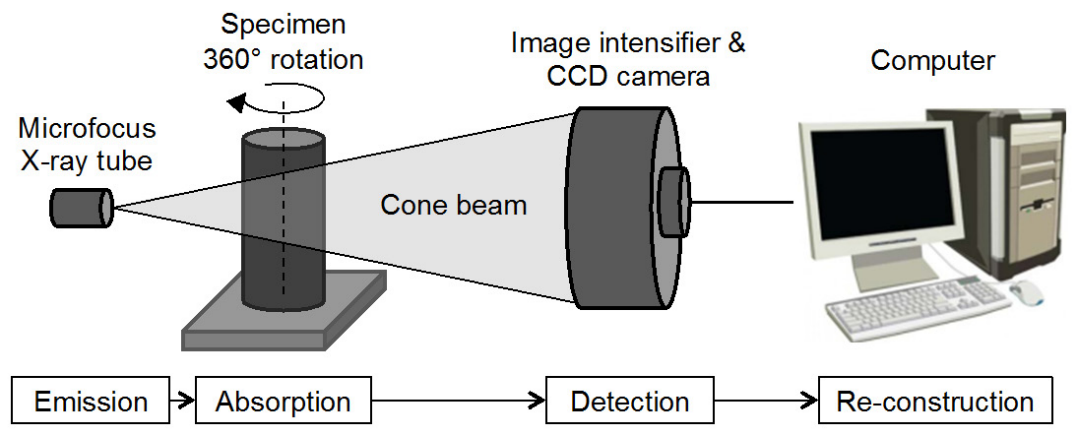

Fig. 3 Set-up for X-ray CT image acquisition. 
In this study, cesium carbonate solution $\left(\mathrm{Cs}_{2} \mathrm{CO}_{3}\right)$ was used as a tracer. It exhibits relatively large atomic number among the alkali metal family. The presence of cesium can be traced from its larger CT numbers as compared with those of cement paste and aggregate in mortar. To determine the relationship between changes in CT number and tracer concentration, preliminary test was conducted as follows. A capillary-glass tube with $2 \mathrm{~mm}$ diameter and $50 \mathrm{~mm}$ length was filled with 0 (water), $0.003,0.030,0.340$ and $1.840 \mathrm{~mol} / \mathrm{L}$ of cesium carbonate $\left(\mathrm{Cs}_{2} \mathrm{CO}_{3}\right)$ solution. Using the same parameters for X-ray CT scanning (e.g. tube voltage, tube current, FCD and FID position described in Section2.3.1), the average CT number of each solution was obtained. Subsequently, the difference between $\mathrm{CT}$ number of each solution and CT number of water is called $\Delta \mathrm{CT}$ number. The $\Delta \mathrm{CT}$ number indicates the change in concentration due to the presence of tracer in solution. Fig. 4 shows the relationship between $\Delta \mathrm{CT}$ number and tracer concentration. It can be seen that the $\Delta \mathrm{CT}$ number is a linear function of tracer concentration. In addition, the CT images in Fig. 4 clearly show that the higher the concentration, the larger the contrast is. Note that such calibration of CT numbers to the density of the object has been performed by several researchers especially for bone tissues (Rho et al. 1995; Couteauet al. 1998). The validity of this technique is thus widely accepted, and it is used at over 4000 centers worldwide (Lang et al. 1998).

\subsection{In-situ diffusion test}

After immersing in water for 24 hours, the specimen was scanned by microfocus X-ray CT to obtain a set of the microtomographic image before diffusion test (initial condition). The focus area for data acquisition was adjusted to the focus area in solution-exposed specimen as far as $2 \mathrm{~mm}$ to $18 \mathrm{~mm}$ from the surface that is exposed to the solution. To prevent the amount of water loss from the crack space during X-ray CT test, experimental set-up shown in Fig. 5(a) was performed in which the bottom region in the specimen was continuously exposed to water. Furthermore, after scanning the specimen of its initial condition, water was removed from the glass tray without changing its position in rotation stage of the microfocus X-ray CT. Then, a cesium carbonate solution of $1.84 \mathrm{~mol} / \mathrm{L}$ concentrations was poured into the glass tray until the specimen becomes submerged at a certain level. The level of the solution was $2 \mathrm{~mm}$ above its bottom edge. The exposure time in the solution is set as follows: 1, 3, 9 and 24 hours. In this way, the observation using X-ray CT during the initial condition and the subsequent diffusion test was made in-situ inside the X-ray machine.

\section{Image analysis}

\subsection{Extraction of 3D crack space from micro- tomographic images}

A cubic volume of interest (VOI) of $600^{3}$ voxels was extracted from the original data set to reduce the computational time for further image analysis. Void space which includes cracks, interconnected and isolated voids could be extracted by selecting a threshold value from the grey-scale value histogram. For void space segmentation, global thresholding was used to separate the void from the "solid" matrix by defining the range of grayscale value (GSV) associated with void voxels. The lower bound of GSV associated with void voxels was set to 0 while the upper bound is set to the void threshold value on the basis of transition point in segmented porosity-threshold dependency curve (Promentilla et al. 2007, 2009).

Furthermore, a basic 3D-image analysis program

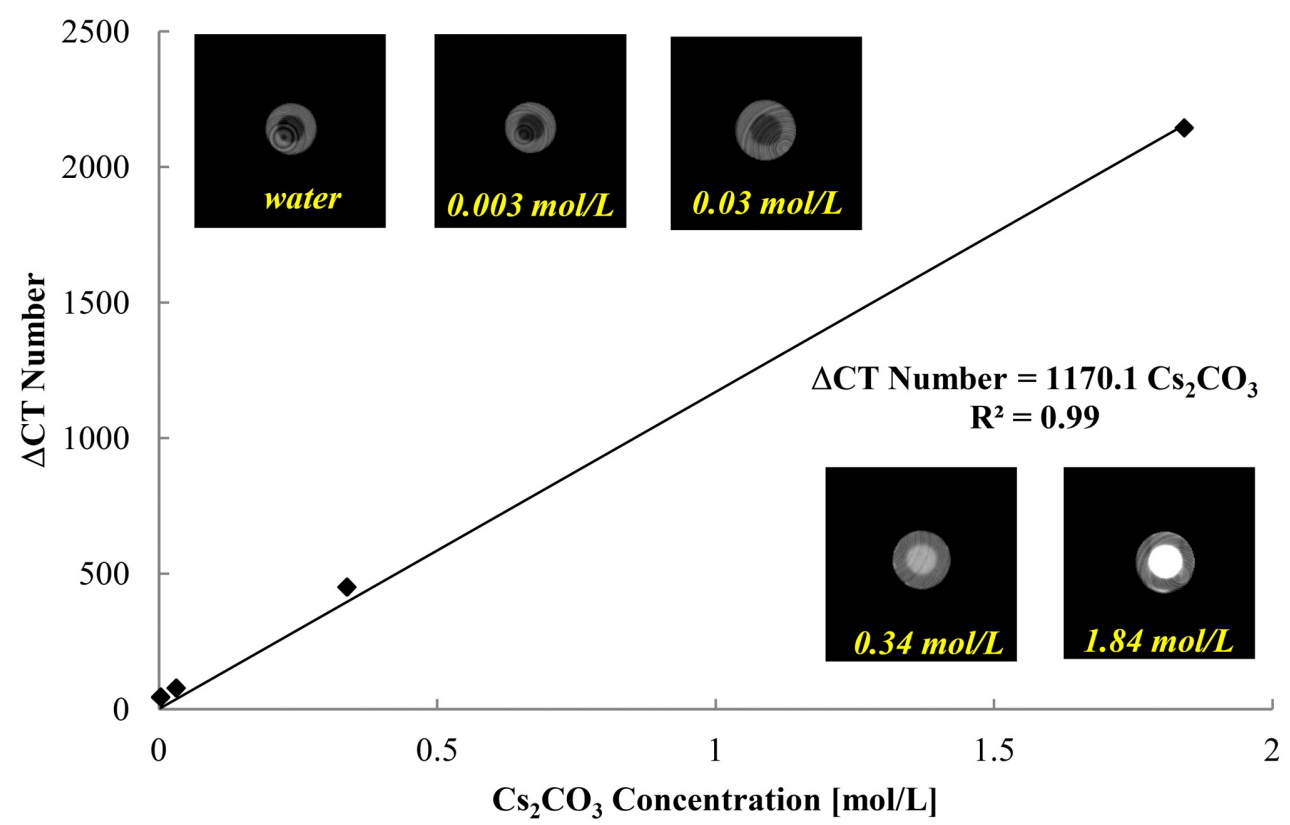

Fig. 4 Relationship between CT number and tracer concentration. 


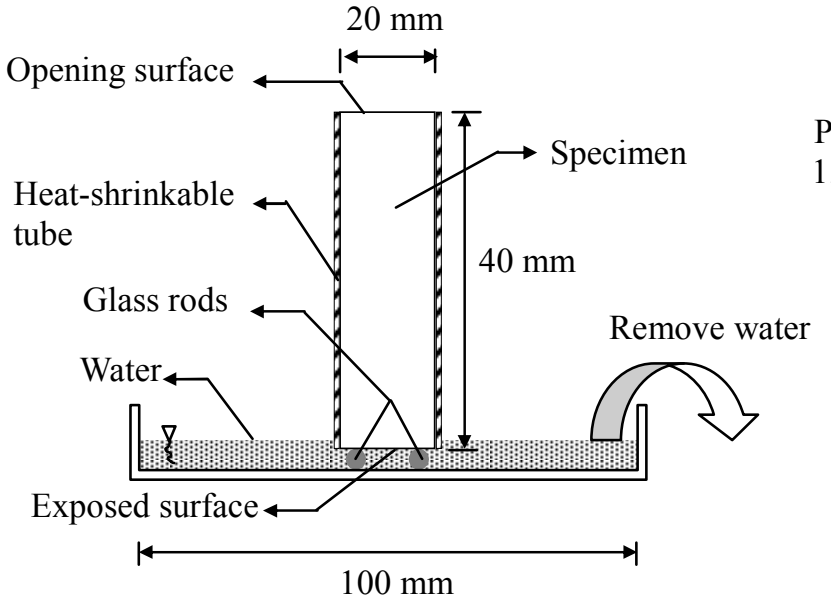

(a)

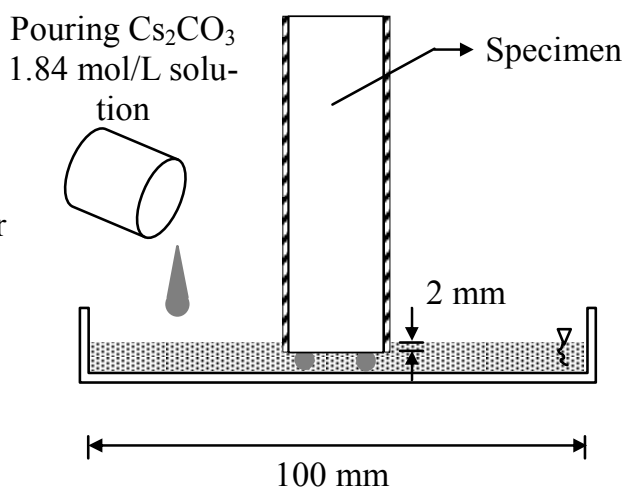

(b)

Fig. 5 Schematics of diffusion test set-up (a) Initial Condition (b) Diffusion test.

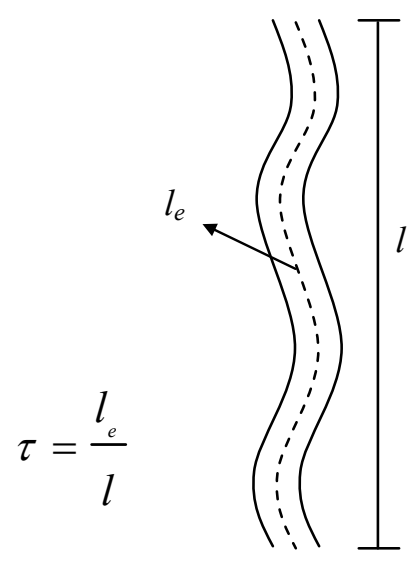

(a)

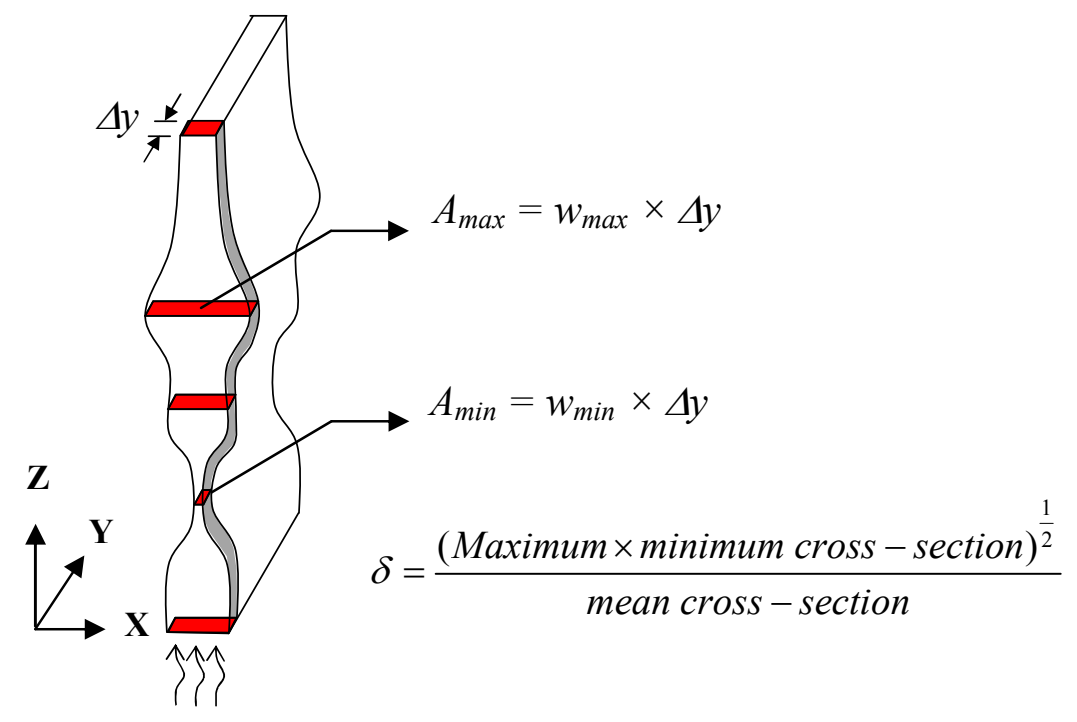

(b)

Fig. 6 Definitions of (a) Tortuosity and (b) Constrictivity.

called SLICE (Nakano et al. 2006), was used to obtain the largest percolating void through cluster multiple labeling technique. This cluster multiple labeling procedure allowed us to identify the largest percolating void cluster if any from the other smaller isolated or dead-end void clusters. In the cracked specimens, the largest percolating void is the connected crack space.

\subsection{Quantification of crack geometry parameter in 3D crack space}

In order to clarify the relationship between crack geometry and diffusion of solute in crack, the crack geometry was first quantified using 3D image analysis. In this study, the crack geometry parameters are defined as geometric tortuosity, and constrictivity. Geometric tortuosity is defined in this study as the ratio of tortuous crack length $\left(l_{e}\right)$ to the nominal crack length $(l)$ as shown in Fig. 6(a).

$$
\tau=\frac{l_{e}}{l}
$$

In a volume of interest (VOI) of $600^{3}$ voxels, the nominal crack length $(l)$ is equal to 600 pixels (see Fig. 7(a)). Meanwhile, in order to determine the tortuous crack length of 3D crack space of each specimen, skeletonization of $3 \mathrm{D}$ crack slice with a thickness of $\Delta y(1$ unit) pixel as show in Fig. 7(b) was applied. Skeletonization is a repeatedly process to remove pixels from the edges of objects in a binary image until they are reduced to single-pixel-wide shapes as shown in Fig. 7(c). This algoritm was implemented using one of the plugins of ImageJ known as BoneJ. BoneJ (Doube et al. 2009, 2010), which is a set of public-domain plugins used for geometry and shape analysis of CT images originally designed for bone tissues. In BoneJ, there are several 


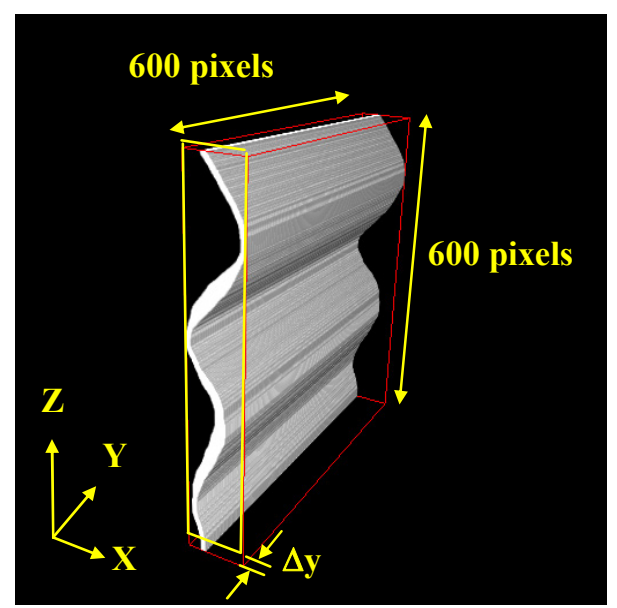

(a)

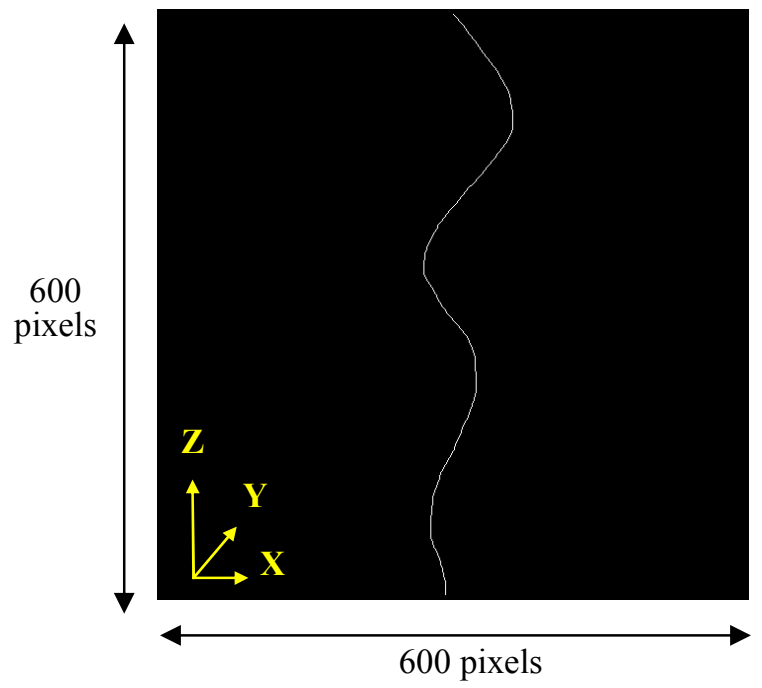

(c)

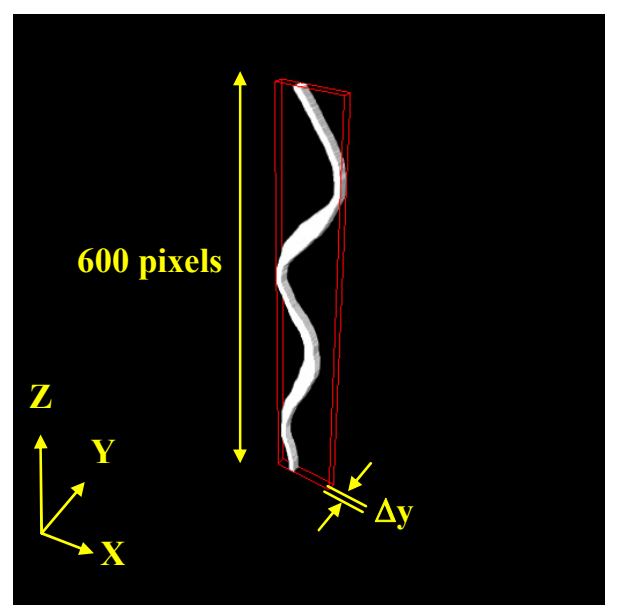

(b)

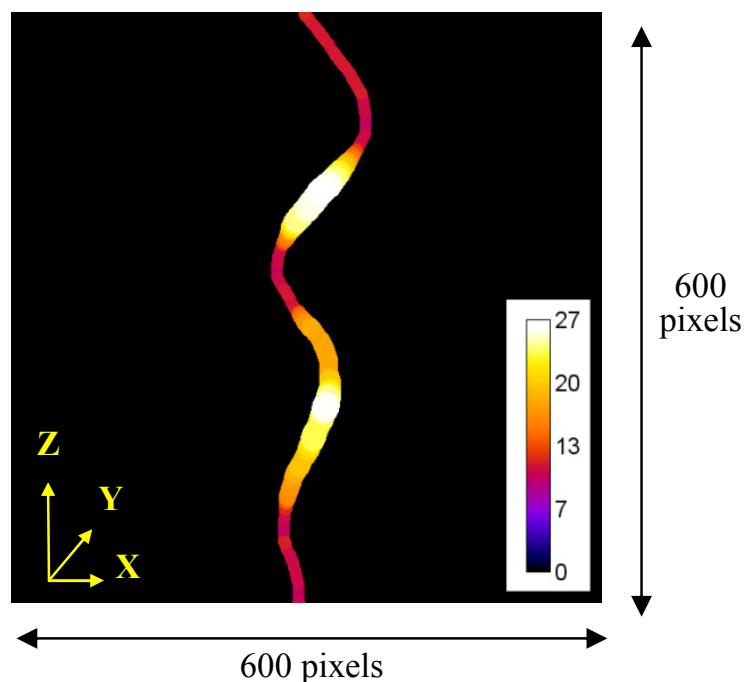

(d)

Fig. 7 Determination of 3D crack geometry (a) 3D artificial crack, (b) Crack slice with a thickness of $\Delta y$ pixels, (c) Skeleton image of crack for AnalyseSkeleton, (d) Crack width distribution as the output of Thickness plugin.

plugins that are suitable for use as well as to analyze crack geometry. For example, AnalyseSkeleton (Arganda-Carreras et al. 2010) was used for measuring tortuous crack length. This plugin tags all pixels or voxels in a skeleton image and then counts all branches, and measures their length. Subsequently, the tortuous crack length $\left(l_{e}\right)$ is then approximated by the total branches (pixels).

Another important parameter in crack is its constrictivity. The constrictivity, $\delta$, accounts for the fact that the cross section of crack varies over its length. For the crack that has perfectly uniform in crack width, the constrictivity is 1 . On the other hand, the constrictivity less than 1 indicates there is a gap between its crack width. The constrictivity of the crack path can then be defined as follows (Currie et al. 1960 and Takahashi et al. 2009)

$$
\delta=\frac{(\text { Maximum } \times \text { minimum } \text { cross }- \text { section })^{\frac{1}{2}}}{\text { mean } \text { cross }- \text { section }}
$$

Mean cross section could be evaluated by linear approximation with average of maximum and minimum cross section. Subsequently, by analogizing that crack is composed of "crack slice" with a thickness of $\Delta y$ pixels, as shown in Fig. 6(b), the constrictivity could be calculated as follows

$$
\begin{aligned}
& \delta=\frac{\left(\left(w_{\max } \times \Delta y\right) \times\left(w_{\text {min }} \times \Delta y\right)\right)^{\frac{1}{2}}}{\frac{1}{2}\left(\left(w_{\max } \times \Delta y\right)+\left(w_{\text {min }} \times \Delta y\right)\right)} \\
& \delta=\frac{\left(w_{\max } \times w_{\min }\right)^{\frac{1}{2}}}{\frac{1}{2}\left(w_{\max }+w_{\min }\right)}
\end{aligned}
$$

where $w_{\max }$ is the maximum crack width; $w_{\min }$ is the minimum crack width.

To calculate the maximum, minimum and mean of 
crack width in percolated crack, another plugins in BoneJ (Doube et al. 2009, 2010) called Thickness (Hildebrand et al. 1997, Dougherty et al. 2007) was performed. The output of the Thickness plugin is the thickness of a 3D object which is displayed in the form of a thickness distribution and thickness map as shown in Fig. 7(d). In this study, the $3 \mathrm{D}$ object is the crack structure and the thickness is defined as the crack width.

\subsection{Determination of tracer diffusion coefficient along the crack}

First, a specific slice at the represented height from the solution contact-exposed surface was chosen from the whole stack of reconstructed slices both in initial and solution-exposed condition. Then, a total of 10 regions of interest of crack filled with tracer were specified. Line segments which intersect perpendicularly to the crack were applied in these regions and were carried out at the same crack section both in initial and solution-exposed condition. The profile of CT number was obtained from each line segment and then compared between those values in initial and solution-exposed condition.

Subtraction between CT number profiles at the same region of cracks in both conditions were done to compute the $\mathrm{CT}$ number difference ( $\Delta \mathrm{CT}$ number) due to tracer diffusion in the cracked mortar. Based on the calibration between the $\triangle \mathrm{CT}$ number and tracer concentration shown in Fig. 4, the average of the maximum the $\Delta \mathrm{CT}$ number was converted into the tracer concentration. Using the said method for specific position of the exposed surface, tracer concentration profiles along the crack were obtained.

It should be noted that this method can only be applied if position and size of the cross section of specimen in reconstructed slices are the same in both conditions. Such condition in the experiment was achieved as there was no change in the position of the specimen on the rotation stage at both initial condition and solution-exposed condition.

Diffusion due to a concentration gradient in one dimension can in general be described by Fick's second law of diffusion as follows:

$$
\frac{\partial c}{\partial t}=D \frac{\partial^{2} c}{\partial x^{2}}
$$

By solving the Fick's second law under proper boundary conditions the penetration of the diffusing species is then described by the following equations:

$$
\frac{C-C_{0}}{C_{s}-C_{0}}=1-\operatorname{erf}\left(\frac{x}{2 \sqrt{D t}}\right)
$$

where $C$ is the concentration of the diffusing species at penetration distance $\mathrm{x}$ at time $\mathrm{t}, C_{s}$ is the constant surface concentration, and $\mathrm{C}_{0}$ is the initial concentration of the diffusing species already present in the bulk phase. $D$ is the diffusion coefficient of the diffusing species and erf is the error function. The diffusion coefficient along the crack is determined from the best-fitted curve represented by Eq.(6) for the measured tracer concentration profile along the crack.

\subsection{Determination of tracer diffusion coefficient perpendicular to the crack wall (through the uncracked body)}

As describe in Section 3.3, similar method was applied to evaluate diffusion coefficient perpendicular to the crack wall (through the uncracked body). In the determination of the diffusion coefficient along the crack, we used the average of the maximum $\Delta \mathrm{CT}$ number profiles, while in the determination of diffusion perpendicular to the crack wall, the whole $\Delta \mathrm{CT}$ number profile is used. The $\Delta \mathrm{CT}$ number profile completely shows the tracer concentration profile through the uncracked body of the mortar at specific height from the solution-exposed surface. The diffusion coefficient perpendicular to the crack wall then was determined from the best-fitted curve represented by Eq.(6) from the measured tracer concentration profile.

\section{Results and discussion}

\subsection{Crack geometry parameters}

Figure 8 describes an example of the VOI and the corresponding $3 \mathrm{D}$ images after void space segmentation and cluster labeling (FA-06-127). The binary image of Fig. $\mathbf{8}(\mathbf{c})$ is produced after the image segmentation process. In this image, the void space (white) which consists of pore and crack can be easily distinguished from the solid (black). In Fig. 8(d), the largest void cluster is separated from both isolated and dead-end void space through cluster multiple labeling procedure. It can be seen that the largest void cluster which is imaged as white represents the crack space. Finally, after separating the largest cluster from the rest in Fig. 8(d), the 3D crack space was obtained (see Fig. 8(f)).

Table 2 summarizes the crack geometry factors derived after extracting the crack from the $\mathrm{CT}$ images. It was found that there were three-dimensional cracks of varied crack widths. The average tortuosity is found to be around 1.25 to 1.26 . This means that in spite of differing mix proportions and crack opening widths, the length of the crack in the specimen, which contains maximum aggregate size of $1.7 \mathrm{~mm}$ and a crack that was induced by a splitting tensile test, was about $25 \%$ longer than the length of specimen.

The constrictivity of FA-06-127 is the largest while OPC-06-152 exhibits equivalent constrictivity to that of OPC-06-51 as shown in Table 2. It is interesting to ob-

Table 2 The crack geometry parameters derived from microtomographic images.

\begin{tabular}{|c|c|c|c|}
\hline Specimen & $\begin{array}{c}\text { Residual } \\
\text { COD }(\mu \mathrm{m})\end{array}$ & $\begin{array}{c}\text { Tortuosity } \\
(\tau)\end{array}$ & $\begin{array}{c}\text { Constrictivity } \\
(\delta)\end{array}$ \\
\hline OPC-06-51 & 51 & 1.25 & 0.54 \\
\hline OPC-06-152 & 152 & 1.25 & 0.59 \\
\hline FA-06-127 & 127 & 1.26 & 0.80 \\
\hline
\end{tabular}




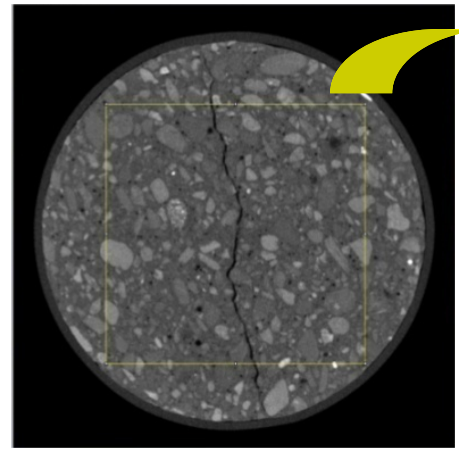

(a)

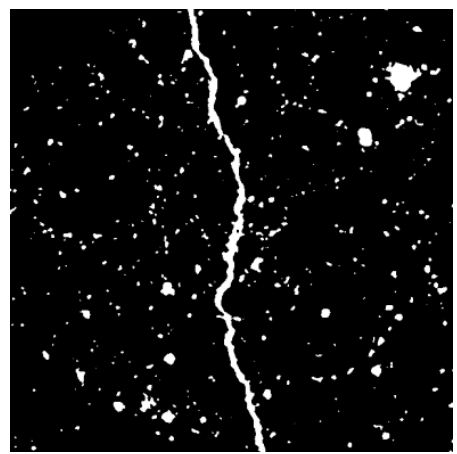

(c)

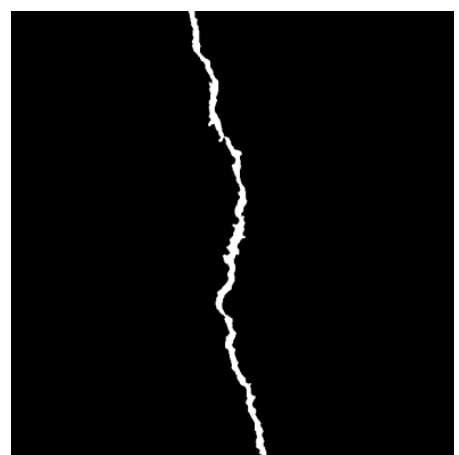

(e)

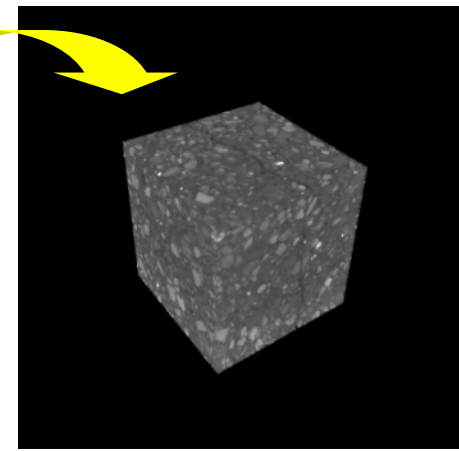

(b)

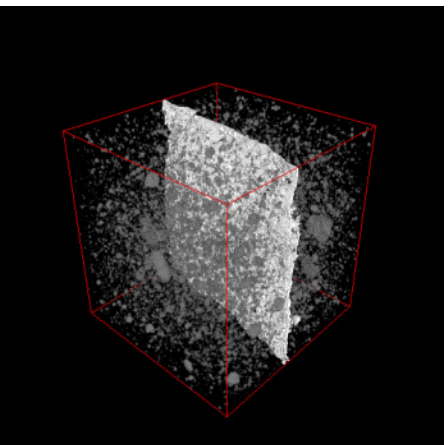

(d)

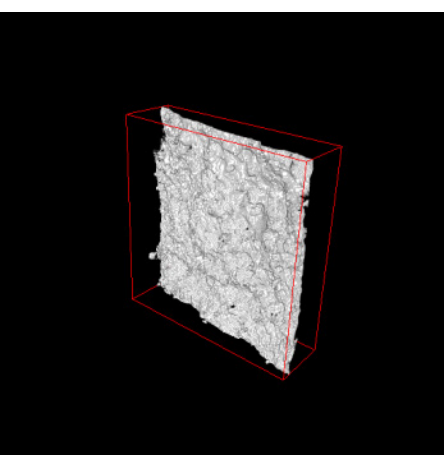

(f)

Fig. 8 Extraction and visualization of crack space from microtomographic images. (a) An 8-bit grayscale image of the representative slice of FA-06-127, (b) The volume of interest (VOI $=600^{3}$ voxel) extracted from the original data set, (c) Void segmentation of the VOI, The void and solid voxels are imaged as white and black, respectively, (d) 3D image of void space where the largest void cluster is imaged as white. The dead-end pore and isolated pore in the VOI are imaged as grey, (e) Crack space as the largest cluster is extracted, (f) 3D image of crack.

tain these findings because the crack opening width of OPC-06-152 is three times larger than that of OPC-06-51 and slightly larger but roughly equivalent to that of FA-06-127. To discuss the different constrictivity the crack width distribution for each specimen were also studied (Fig. 9).

From Fig. 9(a) and (b), it can be seen that both OPC-06-152 and OPC-06-51 have similar crack width distribution between the maximum and minimum value although the frequency of each value of crack width differs. Despite the slightly smaller crack opening width of FA-06-127 as compared with that of OPC-06-152, a smaller range between the maximum and minimum crack width occurred in the FA-06-127 specimen. Hence, crack constrictivity as described by crack width distribution is controlled by the distribution and the mean of the crack width along its length.

In principle, propagation of cracks in concrete always occurs in the weakest areas or areas that require lower energy in order to dissipate the energy due to work load. These areas are the ITZ, unhydrated cement grains, and pores. The presences of these regions in the microstructure of concrete also affect the width of cracks formed by the application of loads. It was found that some sections of the crack of the specimen OPC-06 were formed in pore regions while some parts are around the aggregate. The crack width formed in the pore region was generally larger relative to other crack width along crack length. 


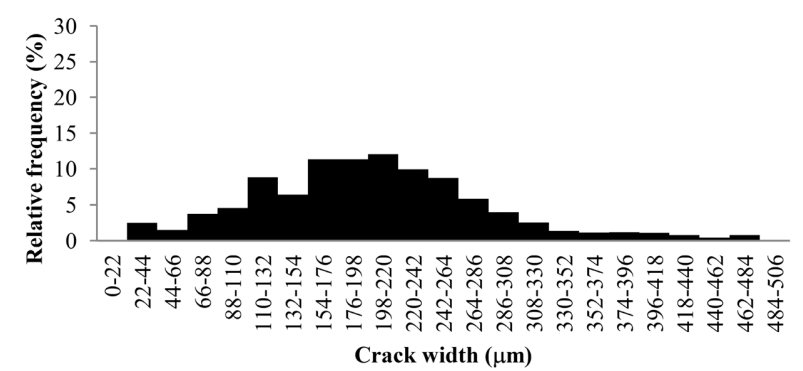

(a)

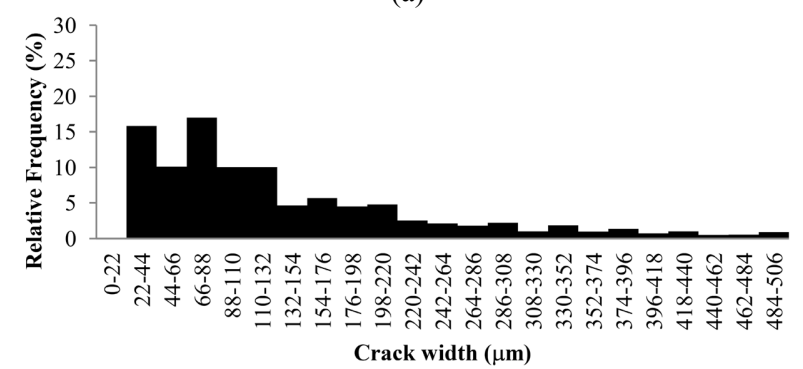

(b)

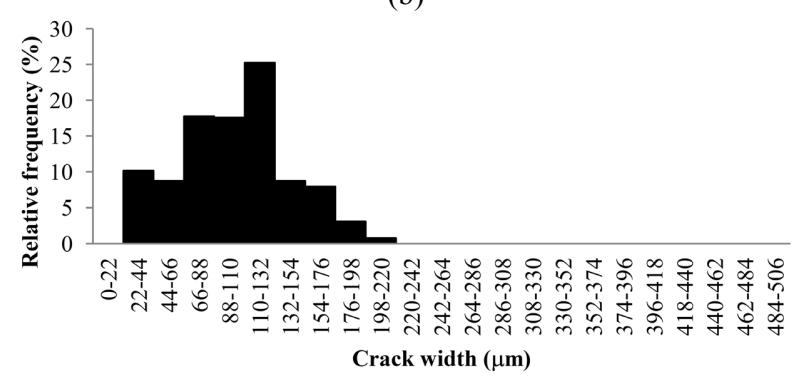

(c)

Fig. 9 Crack width distribution (a) OPC-06-152, (b) OPC-06-51, (c) FA-06-127.

Such condition can obviously lower the degree of the crack width uniformity resulting to an increased variation of crack widths along the crack length (see Fig. 9(a)). In addition, significant effect of constrictivity occurs on the crack that forms a large difference in its width along the crack length. From the observation of cross-sectional image it can also be seen that the addition of fly ash decrease the number of pores in the mortar. The spherical shape of some fly ash particles and the pozzolanic reaction products filled the void that no other parts of the mix can fill, thus creating a more densified material resulting to higher compressive strength for FA-06. Thus, the propagation of cracks generally occurs in the area around the aggregate and cement matrix resulting to a more uniform crack width (see Fig. 9(c)). This means that the cracks that occurred in the specimen FA-06-127 has a higher level of uniformity when compared with the other specimens.

It should be noted that the evaluation of pore structure parameters derived from microtomography images of cementitious material are also influenced by digital resolution (Garboczi et al. 2001, Pignat et al. 1996, Galluci et al. 2007, Promentilla et al. 2009). As for the crack geometry evaluation using X-ray microtomography, it is also influenced by digital resolution. The coarser the pixel size that can be resolved, the crack connectivity decreases which results to a decreases of crack space. This condition has significant effect on crack width distribution which would also affect the constrictivity of crack.

\subsection{Diffusion path of tracer in cracks}

Figure 10(a) to (d) shows the representative microtomographic image of cross section of specimen (OPC-06-152) in intial condition and after 1 hour exposure time in the diffusion test. In Fig. 10(b) and (d) the presence of tracer in the crack is shown in white because of its large CT numbers. The images produced in short periods of exposure time show that the tracer does not fill the entire cavity of cracks. Further observation with the line profile of the CT number (Fig. 10(e) and (f)) provides the finding that the tracer only fills the crack occupied by water. It was thought that the water absorption phenomena in crack during 24 hours pre-soaking periods did not produce fully saturated crack, and leaving behind air pockets. The presence of air in the crack could be an obstacle in the water uptake process as well as the diffusion of tracer. The same phenomenon in which tracer diffuses in water-filled cracks occur in all specimens. In the next exposure time, the results showed that there was no addition of crack space filled by tracer. In this way, the diffusion of tracer only followed the path that formed on the short period of exposure time. This finding implies that for concrete structure in salt-laden environments, the diffusive transport substances such as chloride and magnesium ions in sea water are controlled by the initial condition with regard to the water saturation level inside the crack space.

Figure 11 shows the comparison of the rate of diffusive tracer in the specimens according to the exposure time. The diffusive tracers move quickly deep in the crack and gradually expand to the lateral direction through the wall of the cracks. This is especially true for OPC-06-152 and FA-06-127. No or less diffusive tracer in OPC-06-51 was observed for the exposure times of 1 and 3 hours. As compared to the case with OPC-06-152 and FA-06-127, the diffusive transport in the crack was reduced due to small crack opening width for OPC-06-51.

From Fig. 11, it is clear that OPC-06-152 has more diffusion path compared with other specimens characterized by the large volume of cracks filled by tracer. The higher amount of diffusion path formed on the OPC-06-152 specimen is appeared to cause by higher amount of water filled the crack. This resulted from faster displacement process between the air and water in the crack. In contrast, pre-soaking the OPC-06-51 specimen for 24 hours produced the least diffusion path of tracer. Given the same process of pre-soaking, the diffusion path in the crack is significantly influenced by crack opening width. Such finding indicates the effect of crack opening width on the diffusive transport in cracked concrete. 


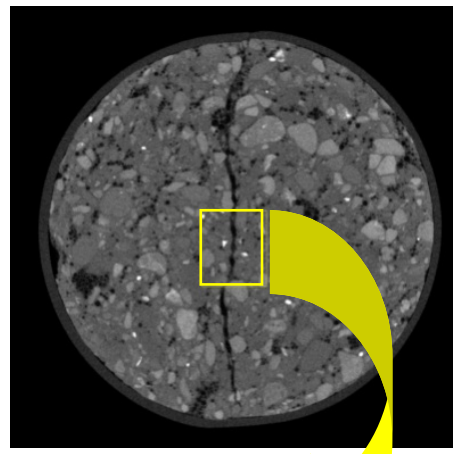

(a)

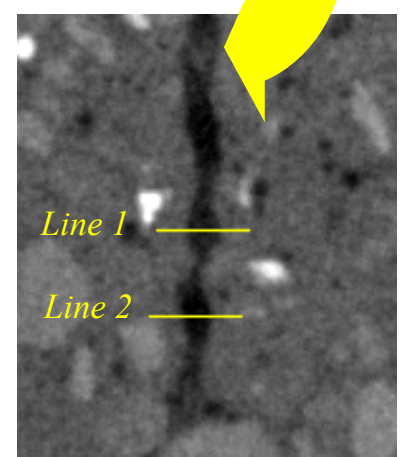

(c)

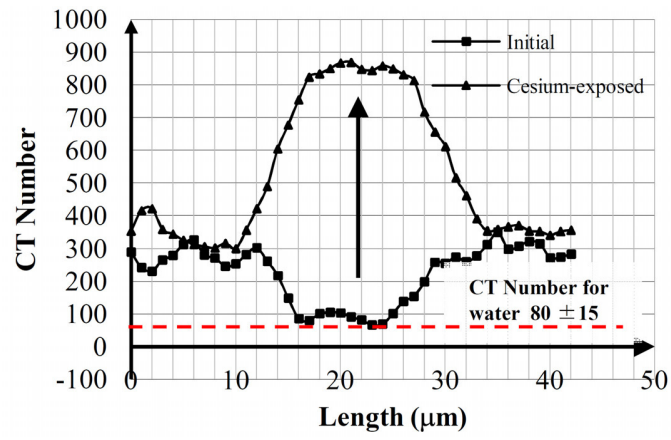

(e)

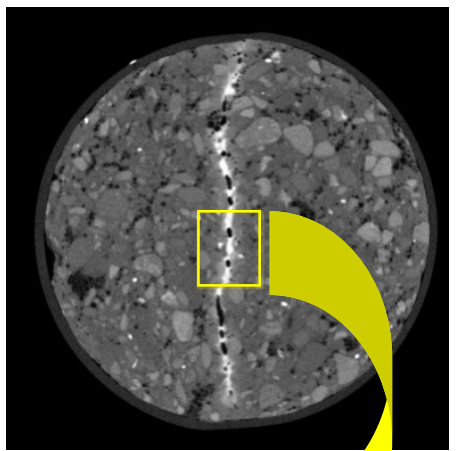

(b)

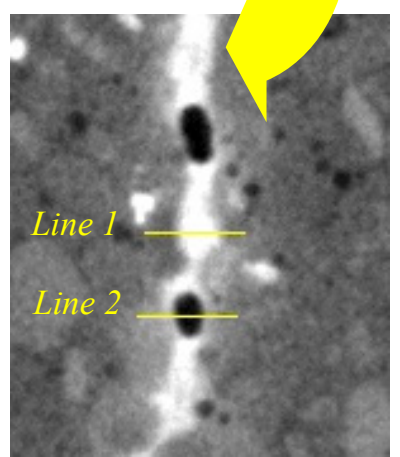

(d)

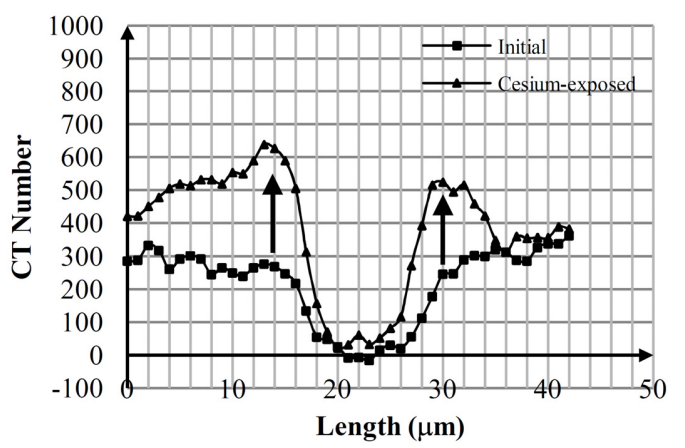

(f)

Fig. 10 Diffusion of tracer in the crack (a) Representative microtomographic image of OPC-06-152 in initial condition (13 $\mathrm{mm}$ from solution-exposed surface), (b) After 1 hour exposure time, (c) Line section applied to obtain CT number profile in initial condition and solution-exposed condition as shown in (d), (e) CT number profile of saturated crack in initial and exposed condition in line 1, (f) CT number profile of unsaturated crack in initial and exposed condition in line 2.

\subsection{Rate of tracer concentration change along the crack}

Figure 12 illustrates an example to obtain the distribution of tracer concentration values in the crack space at a certain elevation from the surface exposed to the solution based from a given line profile (OPC-06-152). Note that the line segment in Fig. 12 is a representative segment selected from among the 10 total segments which were analyzed. From Fig. 12(f) the tracer concentration in the crack was determined to $0.61 \mathrm{~mol} / \mathrm{L}$. This concentration is lower than the solution concentration of $1.84 \mathrm{~mol} / \mathrm{L}$. It means that the diffusion process occurs along the crack passage. The same method was applied to determine the concentration in the crack of OPC-06-152 and FA-06-127 at the height of 5, 9, 13 and $17 \mathrm{~mm}$ from the surface exposed to the solution. For the case of OPC-06-51, determination of tracer concentrations were conducted at 4, 5, 6 and $7 \mathrm{~mm}$ from the surface exposed to the solution. For farther position, the contrast level of crack in the solution-exposed condition was similar to that of initial condition. It was then difficult to select regions of crack filled by tracer for line profile applications. As shown in Fig. 13, tracer diffusion was monitored so as to plot time series of concentration $\left(\mathrm{C} / \mathrm{C}_{\mathrm{s}}\right)$ as a function of transport distance. In Figs. 13(a), (c) and (e), the tracer concentration profiles were obtained. It is obvious that the concentration decreases with the increased heights while increases with exposure times. In addition, from Figs. 13(b) and (d), it can be seen that the rate of tracer was rapid in the first one hour for both 


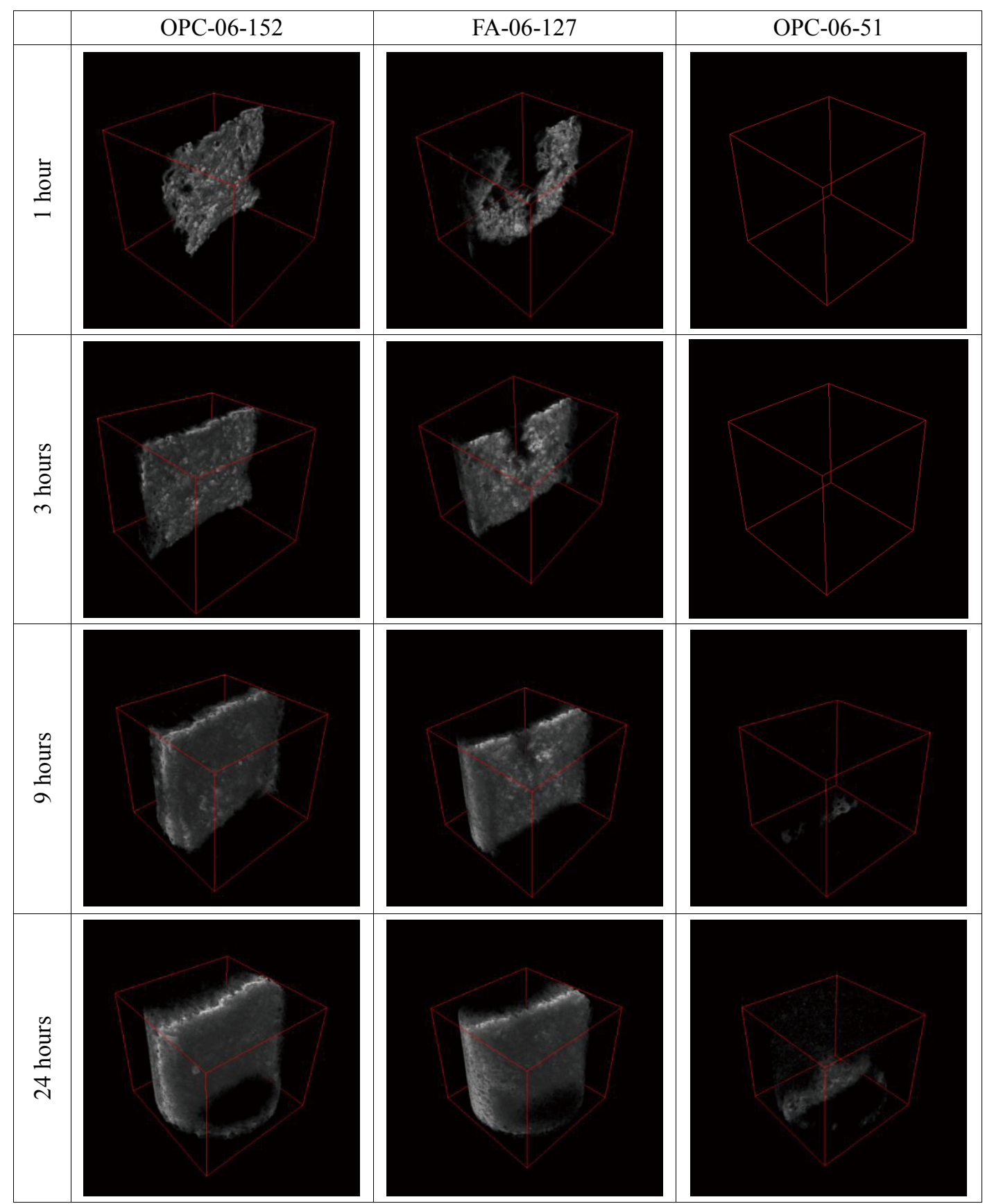

Fig. 11 Three-dimensional image of cesium tracer by specimen and exposure time $(2 \mathrm{~mm}$ to $18 \mathrm{~mm}$ from surface exposed to the solution).

OPC-06-152 and FA-06-127. Afterwards, there is a decrease in the rate of tracer drastically and it tend to be constant for the succeeding exposure time. The presence of tracer in crack in the previous exposure time reduced the concentration gradient which leads to reduced driving force of tracer to diffuse.

For OPC-06-51 specimen, it was found that there was no significant change in CT numbers between initial conditions and the solution-exposed conditions up to 3 hours exposure time (Fig. 13(f)). As discussed in Section 4.2 during those exposure times that the rate of tracer in OPC-06-51 was very slow and difficult to observe. This finding is supported by the results of subtraction images where there is no imprint of tracer left in the crack as shown in Fig. 11.

Diffusion coefficient along the crack was calculated for cesium ion present in the tracer so that the diffusive transport would be quantitatively evaluated and the estimated diffusion coefficients were then compared to the reported values elsewhere (Kumar et al. 1986, Flury et al. 2002, Bucur et al. 2010). The cesium concentration was determined from the calibration of the concentration of cesium carbonate used as tracer in CT images. The diffusion coefficients along the crack for all specimens are 


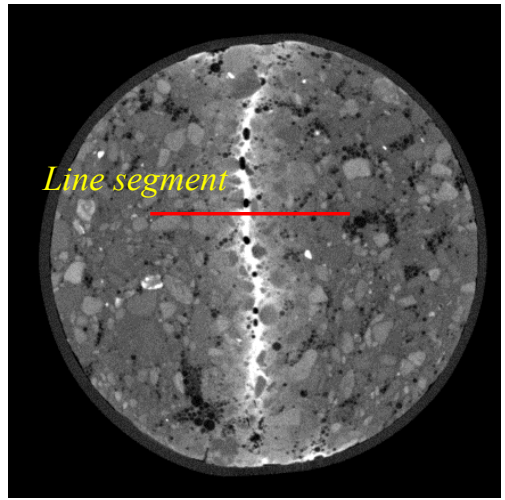

(a)

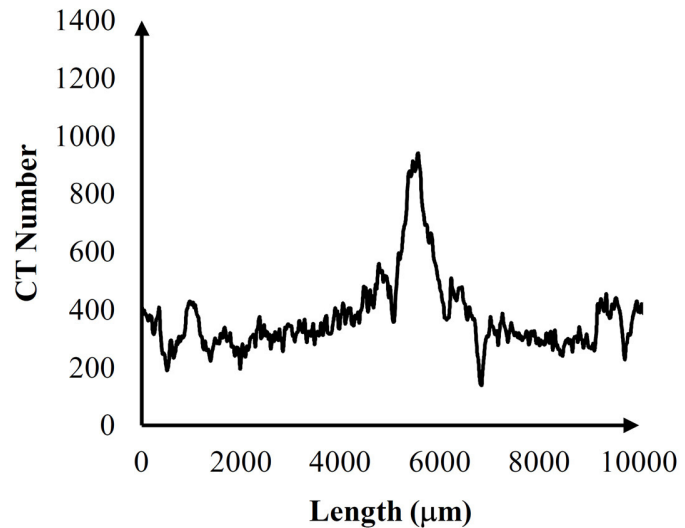

(c)

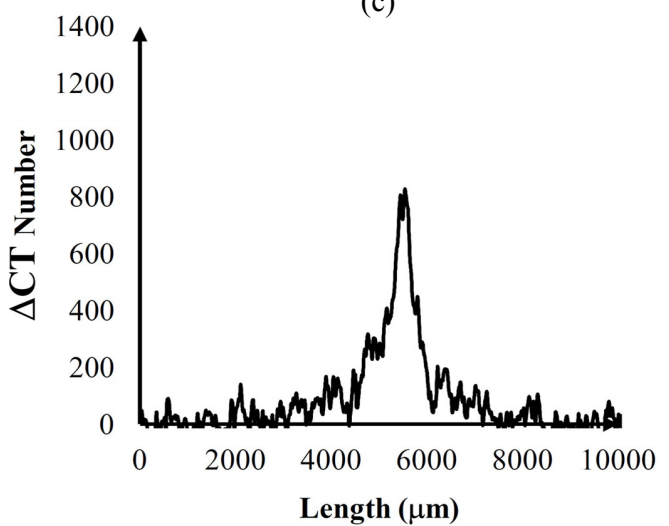

(e)

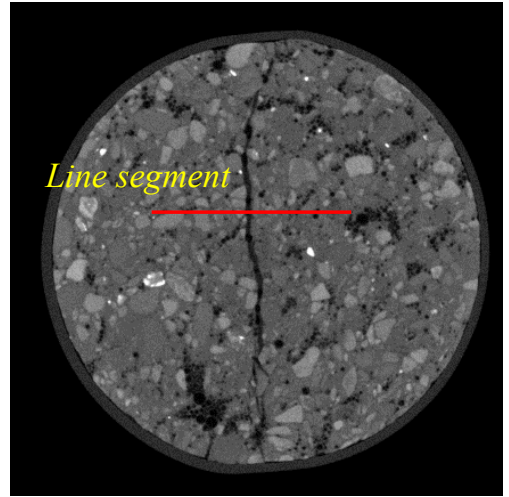

(b)

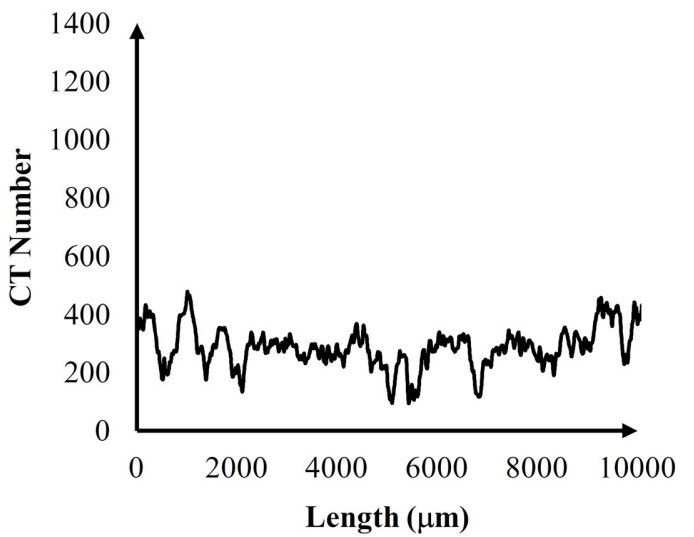

(d)

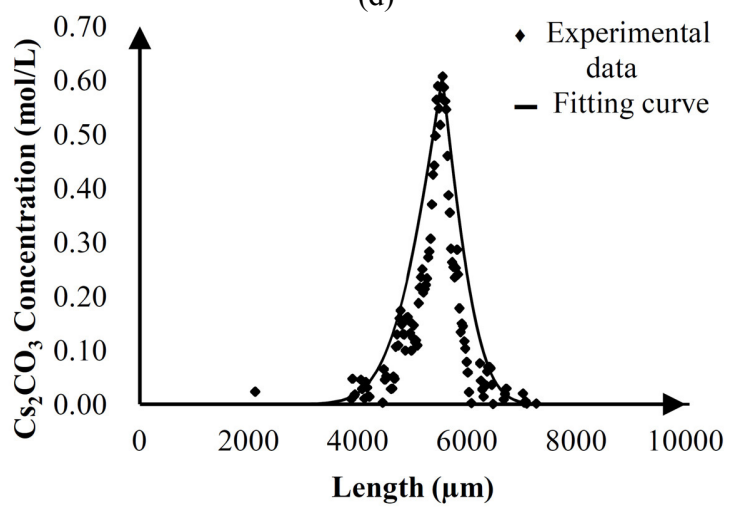

(f)

Fig. 12 A method to determine diffusion coefficient from microtomographic image (OPC-06-152) (a) Line segment is applied at crack filled by tracer in exposed condition, (b) Line segment, which has the same coordinate in initial condition with those of (a), is applied, (c) CT number profile of line segment in solution-exposed condition, (d) CT number profile of line segment in initial condition, (e) Subtracted CT number profile to obtain changes in CT number ( $\Delta C T$ number) due to diffusion of tracer, (f) Tracer concentration profile.

shown in Table 3. The diffusion coefficients were calculated using the concentration profile after the first one hour exposure period and then compared with those calculated for later exposure periods in both OPC-06-152 and FA-06-127. As given in Table 3, the diffusion coefficients are greater than the diffusion coefficient of cesium in free water $\left(2.06 \times 10^{-9} \mathrm{~m}^{2} / \mathrm{s}\right.$, Li et al. 1974 , Flury et al. 2002) in the first one hour. This result implies that during 1 hour exposure time, the mobility of tracer along the crack may involve transport mechanism other than molecular diffusion. However, for the succeeding exposure time the diffusion coefficient decreased drastically up to the level where the diffusion coefficient is lower than the diffusion in the free water. This suggests that at this stage, the mobility of tracer along the crack is restricted but controlled by diffusion.

The crack opening width of FA-06-127, although smaller, could be considered roughly equivalent to that of OPC-06-152 whereas the constructivity of FA-06-127 was larger than that of OPC-06-152 as discussed in Sec- 
Tabel 3 Diffusion coefficients along the crack.

\begin{tabular}{|c|c|c|c|c|}
\hline \multirow{2}{*}{ Specimen } & \multicolumn{4}{|c|}{ Diffusion Coefficient (m $\left.{ }^{2} / \mathrm{s}\right)$} \\
\cline { 2 - 5 } & initial to $1 \mathrm{hr}$ & $1 \mathrm{hrs}$ to $3 \mathrm{hrs}$ & $3 \mathrm{hrs}$ to $9 \mathrm{hrs}$ & 9 hrs to $24 \mathrm{hrs}$ \\
\hline OPC-06-51 & $-^{*}$ & $-*$ & $-*$ & $7.5 \times 10^{-11}$ \\
\hline OPC-06-152 & $4.4 \times 10^{-8}$ & $8.2 \times 10^{-10}$ & $2.5 \times 10^{-10}$ & $9.5 \times 10^{-11}$ \\
\hline FA-06-127 & $3.0 \times 10^{-8}$ & $8.0 \times 10^{-10}$ & $2.4 \times 10^{-10}$ & $9.3 \times 10^{-11}$ \\
\hline
\end{tabular}

tion 4.1. This larger constrictivity could mask the effect of smaller crack opening width on the diffusion process along the crack for FA-06-127. Meanwhile, for the specimen OPC-06-51, the average diffusion coefficient that were calculated from 9 and 24 hours exposure times was smaller when compared to that of OPC-06-152 with the larger crack opening width. Since the presence of water in the crack space provide the preferential path for ion to diffuse, a growing number of crack filled with water would lead to many paths that can be traversed by ion resulting to easier diffusion for ions in larger crack space.

\subsection{Diffusion coefficient perpendicular to the crack wall (through the uncracked body)}

Figure 14 shows the variation of apparent diffusion coefficient of cesium perpendicular to the crack wall according to the distance from the surface exposed to the solution. Although the diffusion coefficients are neither uniform in depth nor constant with time, FA-06-127 generally exhibits lower diffusion coefficients. Porosity and pore connectivity are among the important factors to control the diffusive transport. In addition the presence of aggregate and air void play an important role in the uncracked body of the mortar.

Figure 15 shows the effect of crack width opening and fly ash addition on the average apparent diffusion coefficient of the uncracked body in each mortar specimen. The average value of the apparent diffusion coefficient variation of the uncracked body for OPC-06-152, FA-06-127 and OPC-06-51 are $6.46 \times 10^{-12}, 2.88 \times 10^{-12}$, $5.18 \times 10^{-13} \mathrm{~m}^{2} / \mathrm{s}$, respectively. The apparent diffusion coefficients of cesium ion obtained in this study are considered reasonable and are within reported ranges by previous research (Kumar et al. 1986, Bucur et al. 2010).

For the specimen of OPC-06, the diffusion coefficient was increased with the increasing crack width opening. As described previously, the specimen with larger crack width opening has a higher diffusion rate and hence higher concentration of solute occurred in the crack. Furthermore, higher concentration of solute in the crack increased the penetration of solute towards the uncracked body in mortar. These results suggest that solute content in the crack space governs the supply of the diffusive cesium at the surface area perpendicular to the diffusion in the uncracked body. This could be the reason why the OPC-06-152 exhibited higher diffusion coefficient.

The addition of fly ash led to a reduction of the diffusion coefficient in its uncracked body as compared with that of OPC specimen, although those diffusion coeffi- cients along the crack were almost the same as given in Table 3. Fly ash concrete can normally exhibit increased resistance to diffusivity due to its dense microstructure caused by pozzolanic reaction. Kumar et al. (1986) found that the reduction of the effective diffusion coefficients of cesium ion in cement pastes blended with blast-furnace slag and silica fume. Likewise, it can be said that this observed effect of reduced cesium diffusion can be explained by the fly ash addition to the specimen.

In the determination of the solute concentrations in the uncracked body of mortar, we assumed that there was no tracer diffusion in uncracked body of mortar when CT number during the in-situ diffusion test was less than or equal to $\mathrm{CT}$ number of $300 \pm 25$. The presence of tracer began to be detected if there was an increase in CT number of the uncracked body of mortar. Some open issues may still remain on whether this approach based on the current resolution was relevant to the condition where low concentration of solute is possible in diffusion-accessible pores of the uncracked body of mortar.

\subsection{Modeling diffusive transport along crack}

In order to assess a quantitative relationship between crack geometry and its diffusivity, diffusion coefficient of crack analogous to that of porous medium is defined as follows:

$$
D_{c r}=\frac{\delta}{\tau^{2}} D_{0}
$$

where $\delta$ and $\tau$ are tortuosity and constrictivity of the crack path, and $D_{c r}$ and $D_{0}$ are the diffusion coefficients at the crack and free solution $\left(\mathrm{m}^{2} / \mathrm{s}\right)$, respectively. However, indication from the result suggests that there is another factor controlling the diffusion in the crack which we referred to as diffusion-accessible path, $\xi$. Diffusion-accessible path factor arises since not all cracks can be traversed by solute during diffusion process. So, Eq. (7) may be modified as

$$
D_{c r}=\frac{\delta}{\tau^{2}} D_{0} \xi
$$

In this study, the diffusion coefficients used to determined diffusion-accessible path factor were the average diffusion coefficient values from 1 hour to 24 hours exposure period. It is based on an assumption that in those periods, the mobility of tracer along the crack was controlled by diffusion. The diffusion-accessible path factors, $\xi$, obtained from this study for OPC-06-152, 


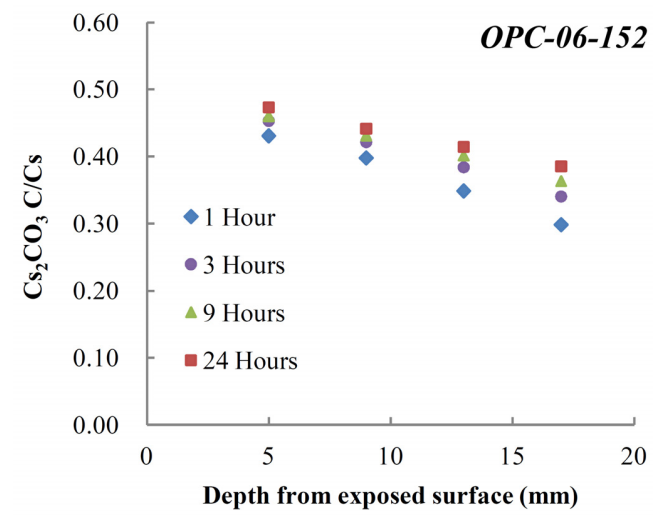

(a)

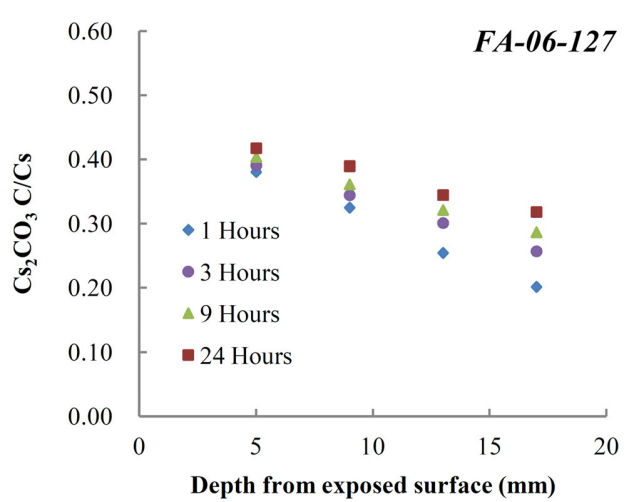

(c)

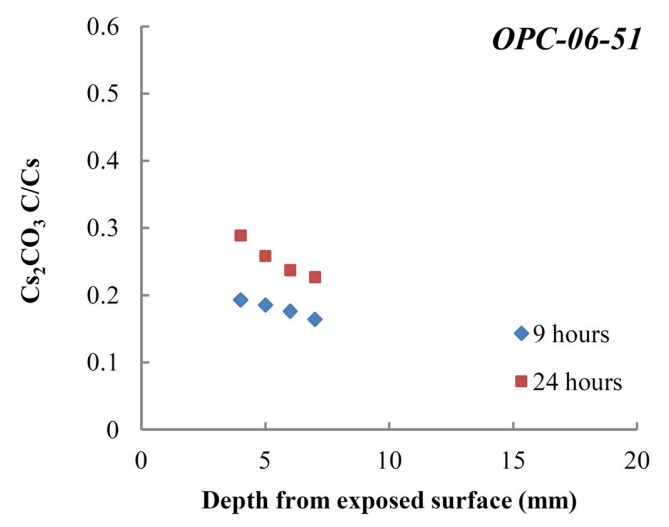

(e)

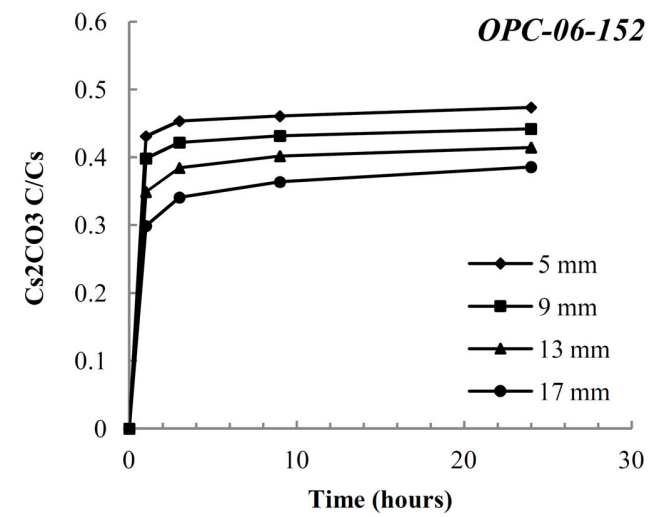

(b)

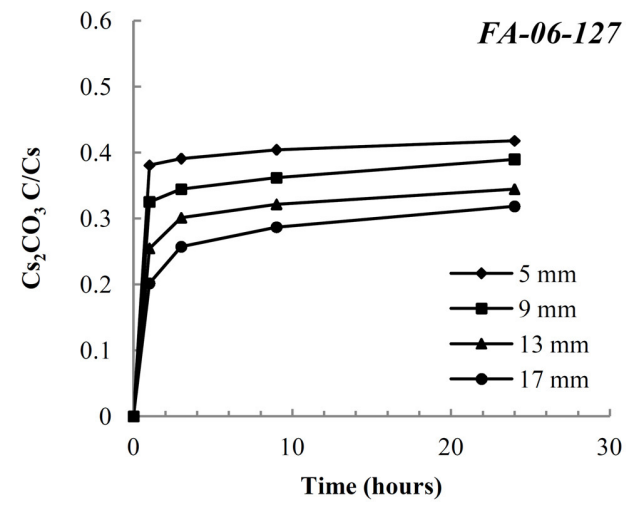

(d)

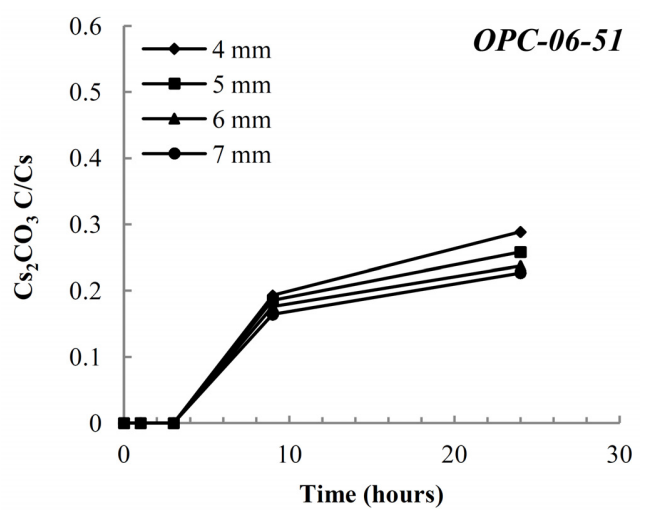

(f)

Fig. 13 Concentration profiles and rate of tracer transport of OPC-06-152 (a) (b), FA-06-127 (c) (d), OPC-06-51 (e) (f).

FA-06-127, and OPC-06-51 were 0.50, 0.40 and 0.11, respectively. These values show the percentage of crack that can be traversed by solute during diffusion process. They are controlled indirectly by saturation degree of crack due to the natural immersion process without any external factors. Higher diffusion-accessible path factor would result from larger crack opening width and would imply less air-filled cavity in the crack. In addition, the quantitative evaluation of diffusion accessible-path factor for the other cases need to be carried out based on a careful design of experiment using predetermined the crack opening width and immersion condition.

\section{Conclusion}

Based on this research, the following conclusions are drawn.

(1) The tortuosity of crack that was induced by splitting tensile test was found to be around 1.25 and it is independent of the addition of fly ash and crack opening width. The cracks of OPC mortars had similar constrictivity irrespective of the different crack opening width. However, the addition of fly ash reduced the constrictivity effect in the crack as compared with that of normal mortars.

(2) Diffusivity in the crack was controlled by the crack opening width, as well as, by its constrictivity. The 


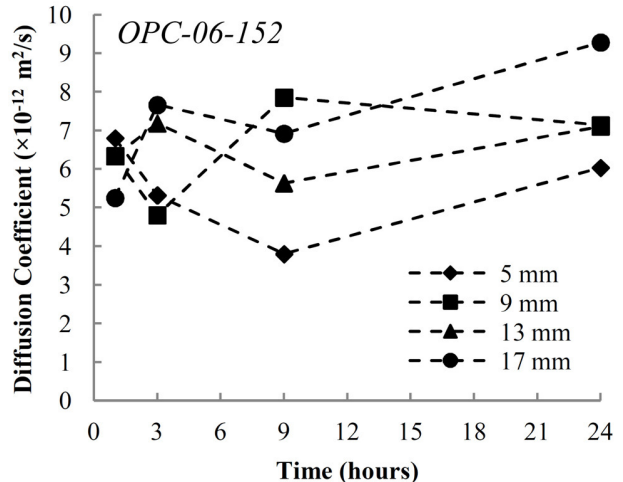

(a)

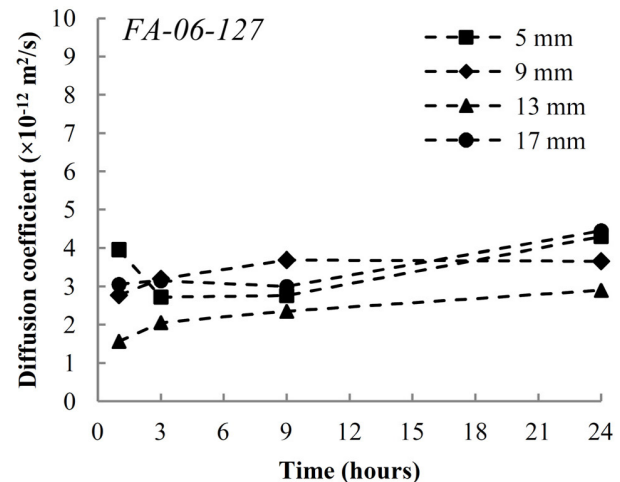

(b)

Fig. 14 Variation in the apparent diffusion coefficients perpendicular to the crack wall (a) OPC-06-152 specimen, (b) FA-06-127 specimen.

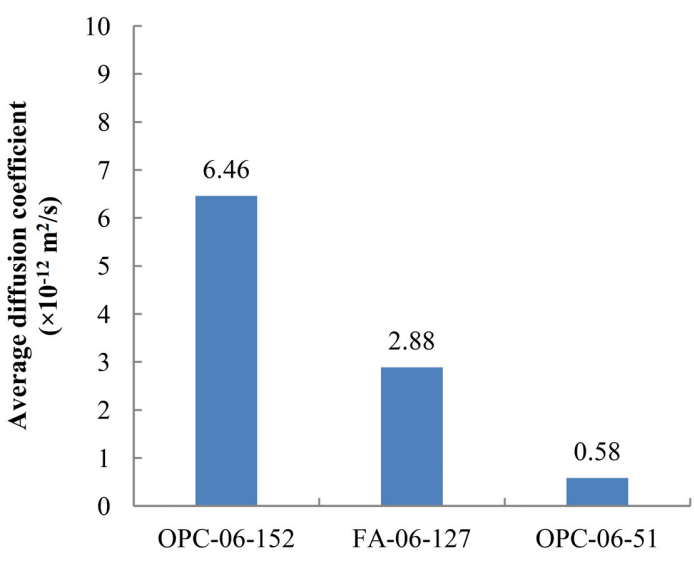

Fig. 15 Comparison of diffusion coefficients perpendicular to the crack wall.

diffusive transport was also restricted due to the presence of air pockets in the crack. The restricted mobility of solute increased with the decreased crack opening width. In this regard, a diffusion-accessible path factor was proposed to account for the degree of water saturation within the crack space.

(3) The rate of solute in the crack space was rapid in the first one hour for both OPC and fly ash specimens with equivalent crack opening width. The early period in the diffusion in cracked mortar exposed to the solution strongly influenced the rate of solute transport for the succeeding exposure time.

(4) It was confirmed that the addition of fly ash could reduce the diffusivity through the uncracked body as compared with normal OPC mortar of equivalent diffusion coefficient along the crack. Diffusivity in uncracked body was increased with the increased crack opening width because of the higher concentration at the surface of the crack wall.

\section{Acknowledgment}

Part of this research was funded by Japan Society for Promotion of the Science (Research No.23360187). The first author also expresses gratitude for the financial support from JICA.

\section{References}

Al, T., Agbogun, H. M. D. and Hussein, E. M. A., (2013). "Three dimensional imaging of porosity and tracer concentration distribution in a dolostone sample during diffusion experiments using X-ray micro-CT." Journal of Contaminant Hydrology, 145(1), 44-53.

Arganda-Carreras, I., Fernández-Gonzáles, R., Muñoz-Barrutia, A. and Ortiz-De-Solorzano, C., (2010). "3D reconstruction of histological sections: application to mammary gland tissue." Microsc. Res. Tech., 73(11), 1019-1029.

Bentz, D. P., Quenard, D. A., Kunzel, H. M., Baruchel, J., Peyrin, F., Martys, N. S. and Garboczi, E. J., (2000). "Microstructure and transport properties of porous building materials. II: Three-dimensional X-ray tomographic studies." Materials and Structures, 33, 147-153.

Bucur, C., Olteanu, M., Cristache, C. and Pavelescu, M., (2010). "Radionuclide transport through cement matrices." Revista De Chimie, 61(5), 458-461.

Burlion, N., Bernard, D. and Chen, D., (2006). "X-ray microtomography: Application to microstructure analysis of a cementitious material during leaching process." Cement and Concrete Research, 36, 346-357.

Cavé, L., Al, T., Xiang, Y. and Loomer, D., (2010). "Investigation of diffusive transport process in sedimentary rock." Report of Nuclear Waste Management Organization, NWMO TR-2010-04.

Couteau, B., Hobatho, M., Darmana, R., Brignola, J. and Arlaud, J., (1998), "Finite element modeling of the vibrational behavior of the human femur using CT-based individualized geometrical and material properties." Journal of Biomechanics, 31, 383-386.

Currie, J. A., (1960). "Gaseous diffusion in porous media." Parts1 and 2, Br. J. Appl. Phys, 11, 314-324.

Doube, M., Klosowski, M. M., Argenda-Carreras, I., Cordelières, F. P., Dougherty, R. P., Jackson, J. S., Schmid, B., Hutchinson, J. R. and Shefelbine, S.J., (2010). "BoneJ: Free and extensible bone image analysis in ImageJ." Bone, 47, 1076-1079.

Doube, M., (2009). "BoneJ [online]." Available from: 
$<$ http://bonej.org $>$ [Accessed December 2012].

Dougherty, R. and Kunzelmann, K., (2007). "Computing local thickness of 3D structures with ImageJ." Microsc. Microanal., 13(Suppl 2), 1678-1679.

Flury, M. and Gimmi, T., (2002). "Solute diffusion." In: J. H. Dane, G. C. Topp Eds. Methods of Soil Analysis, Part 4, Physical Methods, Soil Science Society of America, Madison, WI, 1323-1351.

Gallucci, E., Scrivener, K., Groso, A., Stampanoni, M. and Margaritondo, G., (2007). "3D experimental investigation of the microstructure of cement pastes using synchrotron X-ray microtomography." Cement and Concrete Research, 37, 360-368.

Garboczi, E. J. and Bentz, D. P., (2001). "The effect of statistical fluctuation, finite size error, and digital resolution on the phase percolation and transport properties of the NIST cement hydration model." Cement and Concrete Research, 31(10), 1501-1514.

Helfen, L., Dehn, F., Mikulik, P. and Baumbach, T., (2005). "Three-dimensional imaging of cement microstructure evolution during hydration." Advances in Cement Research, 17(3), 103-111.

Hildebrand, T. and Rüegsegger, P., (1997). "A new method for the model-independent assessment of thickness in three-dimensional images." $J$ Microsc, $185,67-75$.

Hitomi, T., Mita, Y., Saito, H. and Takeda, N., (2004). "Observation of fine structure of mortar using X-ray CT images at SPring-8." Proceedings of Annual Conference of Japan Concrete Institute, 26(1), 645-650 (in Japanese).

Ikeda, S., Sugiyama, T., Kikkawa, T. and Shimura, K., (2012). "Study on transport phenomenon in crack using the cesium carbonate as a tracer by X-ray CT." Proceedings of the Concrete Structure Scenarios of JSMS, 12, 207-212 (in Japanese).

Jang, S. Y., Kim, B. S. and Oh, B. H., (2011). "Effect of crack width on chloride diffusion coefficient of concrete by steady-state migration test." Cement and Concrete Research, 41(1), 9-19.

Kikkawa, T., Sugiyama, T., Darma, I. S. and Shimura, K., (2012). "Observation of flexural cracking and cesium carbonate transport using X-ray CT." Proceedings of Annual Conference of Japan Concrete Institute, 34(1), 1810-1815, (in Japanese).

Kumar, A. and Roy, D.M., (1986). "Retardation of Cs ${ }^{+}$ and $\mathrm{Cl}^{-}$diffusion using blended cement admixtures." Journal of American Ceramic Society, 69(4), 356-360.

Landis, E. N. and Nagy, E. N., (2000). "Three-dimensional work of fracture for mortar in compression." Engineering Facture Mechanics, 65, 223-234.

Landis, E. N. and Keane, D. T., (2010). "X-ray microtomography." Materials Characterization, 61, $1305-1316$.
Lang, T., Augat, P., Majumdar, S., Ouyang, X. and Genant, H. K., (1998), "Noninvasive assessment of bone density and structure using computed tomography and magnetic resonance." Bone, 22(5), 149S-53S.

Li, Y. H. and Gregory, S., (1974). "Diffusion of ions in sea water and in deep-sea sediment." Geochimica et Cosmochimica Acta, 38, 703-714.

Lu, S., Landis, E. N. and Keane, D. T., (2006). "X-ray microtomographic studies of pore structure and permeability in Portland cement concrete." Materials and Structures, 36, 11-20.

Nakano, T., Tsuchiyama, A., Uesugi, K., Uesugi, M. and Shinohara, K., (2006). "SLICE - Software for basic 3-D image analysis [online]." Japan Synchrotron Radiation Research Institute (JASRI), Available from: $<$ http://www-bl20.spring8.or.jp/slice/> [Accessed 5 December 2012].

Pignat, C. and Navi, P., (1996). "Simulation of cement hydration and the connectivity of the capillary pore space." Advanced Cement based Material, 4(2), 58-67.

Polak, A., Grader, A., Wallach, R. and Nativ, R., (2003). "Chemical diffusion between a fracture and the surrounding matrix: measurement by computed tomography and modeling." Water Resource Research, 39(4), 1106.

Promentilla, M. A. B., Sugiyama, T., Hitomi, T. and Takeda, N., (2008). "Characterizing the 3D pore structure of hardened cement paste with synchrotron microtomography." Journal of Advanced Concrete Technology, 6(2), 273-286.

Promentilla, M. A. B., Sugiyama, T., Hitomi, T. and Takeda, N., (2009). "Quantification of tortuosity in hardened cement paste using synchrotron-based X-ray computed microtomography." Cement and Concrete Research, 39(6), 548-557.

Promentilla, M. A. B. and Sugiyama, T., (2010). "X-Ray Microtomography of mortars exposed to freezing-thawing action." Journal of Advanced Concrete Technology, 8(2), 97-111.

Rho, J., Hobatho, M. and Ashman, R., (1995). "Relations of mechanical properties to density and CT numbers in human bone." Medical Engineering \& Physics, 17, 347-355.

Sugiyama, T., Promentilla, M. A. B., Hitomi, T. and Takeda, N., (2010). "Application of synchrotron microtomography for pore structure characterization of deteriorated cementitious materials due to leaching." Cement and Concrete Research, 40(8), $1265-1270$

Takahashi, H., Seida, Y. and Yiu, M., (2009). “3D X-ray CT and diffusion measurements to assess tortuosity and constrictivity in a sedimentary rock." diffusion-fundamentals.org, 11(89), 1-11. 